(C) Springer-Verlag 1991

\title{
Orthopédie-Traumatologie A new periodical on Orthopaedics-Traumatology, what for?
}

The S. O. T. EST (Société d'Orthopédie-Traumatologie de l'Est de la France) and the GECO (Groupe d'Etude pour la Chirurgie Osseuse) have just united in order to co-edit, under the banner of Springer-Verlag France a new periodical of orthopaedics-traumatology in quarterly issues, this one being the first copy. This new publication aims at several ambitions ; enabling both founding societies to publish works referred in important international bibliographies, enabling the largest number of young surgeons, particulary assistant of departments for the French, to see their works published, national publications being over burdened and saturated, getting open the European dialogue, at the dawn of a Europe which, even if it encounters difficulties in finding its political dimension, already exists with no limitation within ideas and sciences.

The S.O.T.EST, born in 1973, brings together approximately 250 members, mainly orthopaedic surgeons and traumatologists, but also hand surgeons, rheumatologists, physiotherapists, anaesthetists, from the five regions of "Greater East" of France, namely Alsace, Bourgogne, Champagne-Ardennes,
Franche-Comté and Lorraine but also from Germany, Belgium, Italy, Luxembourg and Switzerland. It organizes each year a great meeting, with as a rule two major themes and free papers, in one of its numerous urban centres, sometimes within university hospitals, sometimes non-university, public or private. For the last four years, two very enriching French-German meetings have been held and in former time French-Belge and French-Switzerland meetings too.

The GECO was born in 1976 wih the leading idea of offering a platform to annual meetings on orthopaedics and traumatology themes, in an atmosphere of Winter-skiing, where, while combining sports activities with work, orthopaedics and traumatology surgeons from all backgrounds, universitarian or not, can meet, free of any formalism. The founding and entitled members agree on putting their files together each year in order to lead to a Round Table which is then published as reports. More than 20 reports have been published. The GECO sessions are naturally open to participants other than the mere holders, and represent each year in January a must for nume- rous regulars members. In january 1991 the XVth Broaden Meeting took place with 160 surgeons participating. Since two years now, the GECO meetings are bilingual, in French with English interpreting.

The European origin of the S.O.T. EST members, the central position, Lotharingian, of the Greater Eastern French Region, the will for a European opening of the GECO on the other hand, did lead us to require a "European" periodical, materialized in an issue published straight away in French and English with abtracts in each language. One does not call oneself European, one really is or not. Conscious of being European every passing day, thanks to our geographical and cultural environment, we wish to add, by means of this periodical, a solid brick to the new building being raised on our old continent.

Professor Pierre Kehr

Professor Henry Coudane

Chief Editors 